\title{
Investigation of Physical Fitness Parameters of 7-9 Years Groups Male Students that have Training in Different Sports Branches
}

\author{
Meltem Kurt ${ }^{1}$ \\ Alpaslan Kartal ${ }^{2}$
}

1.2 Tozgat Bozok University, School of Physical Education and Sports, Yozgat, Turkey.

${ }^{2}$ Email:meltemkurt@okyanuskoleji.k12.trTel:+905462977477

Email: akartal6161@hotmail.com Tel:+905326952076

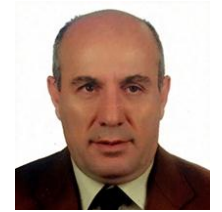

Corresponding Author

\begin{abstract}
The fact that children have acquired the habit of physical activity therefore becoming physically and mentally healthy individuals has an important role in the formation of a healthy society. Physical activities during childhood and adolescence ensure that sports performance is at the highest level and also contributes to overall health values (Saygin, Karacabey, \& Saygin, 2011). The aim of this study is to compare the physical fitness parameters of the male students who take the physical education course with an average age of 7,15 \pm 36 years and who are trained in different sports branches. The first-grade students of the Private Yükselen College, who were in Pursaklar District of Ankara Province, participated in the study. For this purpose, physical fitness tests of 65 male students who took courses of physical education and received training in different sports branches were conducted. Significance values were taken as $p<0.01$ and $p<0.05$. As the results of the study showed that the speed, agility and muscular force parameters of the males showed faster development, it was observed that the values of the students who took education in different branches were better and a significant difference was observed between them.
\end{abstract}

Keywords: Sports, Physical fitness, Physical education, Student, Anthropometric measurements.

Citation | Meltem Kurt; Alpaslan Kartal (2020). Investigation of Physical Fitness Parameters of 7-9 Years Groups Male Students that have Training in Different Sports Branches. Asian Journal of Education and Training, 6(1): 99-104

History:

Received: 20 November 2019

Revised: 2 January 2019

Accepted: 5 February 2020

Published: 97 February 9090

Licensed: This work is licensed under a Creative Commons

Attribution 3.0 License (oc)

Publisher: Asian Online Journal Publishing Group
Acknowledgement: Both authors contributed to the conception and design of the study.

Funding: This study received no specific financial support

Competing Interests: The authors declare that they have no conflict of interests.

Transparency: The authors confirm that the manuscript is an honest, accurate, and transparent account of the study was reported; that no vital features of the study have been omitted; and that any discrepancies from the study as planned have been explained.

Ethical: This study follows all ethical practices during writing.

\section{Contents}

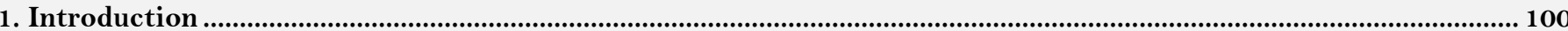

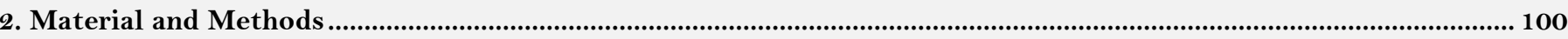

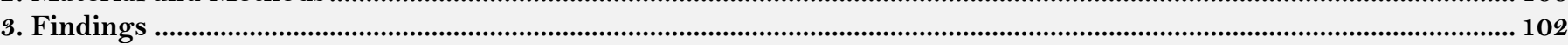

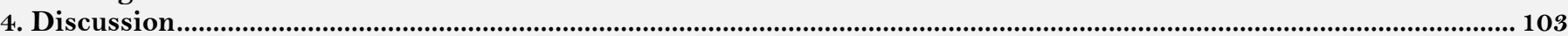

References 


\section{Contribution of this paper to the literature}

This study contributes to the existing literature by comparing the physical fitness parameters of the male students who take the physical education course with an average age of 7,15 \pm 36 years and who are trained in different sports branches.

\section{Introduction}

Physical health gained during childhood and at the same time maintained throughout life is considered necessary to be a healthy individual and to show a high level of capacity. Therefore, exercise training can start at an early age that the child can do (Baltacı, 2008).

Physical activities carried out during children and adolescents ensure high sports performance (Saygın et al., 2011). The period of basic movements and sports-related movements constitute the age group of 7-10. Another reason for the determination of physical properties at an early age is the determination of physical fitness levels. Ability selection can be supported by determining physical fitness levels. This way, young athletes can be guided correctly (Celik, Günay, \& F., 2013).

At the same time, sports help children to pay attention to something, focus better on a task and increase their imagination. The easiest way to support children is in physical education classes. The basic education stage shows interesting aspects of the child's movement experience. There is no doubt that movement and play education lessons, play an important role on physical fitness parameters in the developmental stage of children (Yenal, Çamliyer, \& Saracaloğlu, 1999).

In this context, it may be possible to achieve the desired goals in sports, to give importance to education and training as the most important priority and to train the instructors in sports in accordance with scientific measures.

Physical fitness parameter development in children;

Cardiovascular Endurance: Aerobic endurance capacity in childhood increases with age. There is no different development in girls and boys; shows the same development. Lung volume continuously increases until it reaches full growth (Emiroğlu, 2004).

Muscular Strength and Endurance: Total muscle mass in men is $25 \%$ of body weight at birth and $40 \%$ or more in adulthood. The length of the muscles is directly proportional to the length of the bones. Without increasing exercise and diet muscle mass is the highest level in boys at the age of 18-25 years (Zorba, 2001).

Flexibility: Flexibility of children between the ages of 5-8 is fixed. It reaches the highest level until the age of 12-13. Then it decreases with age. Since muscle tissue prolongs in response to the increase in bone length in prepuberty, a decrease in joint flexibility is observed during rapid growth (Zorba, 2001).

Balance: Motor function components; balance and vision are done by the connection between deep sensory organs and motor systems. Balance is to maintain a position in a certain place. Basic forms of balance in parallel with child development; sitting, standing, turning, bending, reaching up, standing on one leg, or different forms. From an early age, balance is the key to movement training (Kesilmis, 2012).

Speed: In sports, speed means the most intensive application of human motoric actions in the shortest period of time. In another words; "The ability to react as soon as possible to a stimulus result". Speed development, which is low before school age, increases rapidly from this period up to the age of 13 years. A good reaction rate can be achieved at age 9-10. While latent duration was between 0.50 and $0.60 \mathrm{sec}$ in children aged 6-7 years, for 10-yearolds it decreases until between $0.25-0.40 \mathrm{sec}$. Reaction speed during the second school age reaches almost the value of adults (Kesilmis, 2012).

The aim of this study is to examine and compare the physical fitness parameters of male students who are in the course of physical education and who are also trained in different sports branches.

\section{Material and Methods}

\subsection{Study Group}

The study was conducted to compare the physical fitness parameters of male students who took physical education courses and also studied in different sports branches and 65 male students with a mean age of $7.15 \pm 36$ years. Out of 65 male students, 40 students attend only play and physical activity courses, while the remaining 25 students take training in different sports branches in addition to physical education courses. Necessary permissions were obtained before the tests were performed and the test process was explained to the students.

\subsection{Data Collection Tools}

$50 \%$ of the first-grade students who have been studying at Yukselen College in Pursaklar District of Ankara have been directed to research. The research was conducted after the first individual consent of the students and the voluntary participation of their families. Physical fitness parameters were made using Eurofit test battery parameters considering the average age of the students.

In the Pursaklar District of Ankara, 65 people who participated in the study applied physical fitness tests determined by the researcher to the first-grade male students. Anthropometric measurements (length, body weight, body mass index), flexibility test, balance test, standing jump test, 10x5 meter shuttle test, 30-meter sprint test, t-agility test and 20-meter shuttle test were applied respectively. The tests were performed twice and the best values were evaluated for analysis.

\subsection{Anthropometric Measurements \\ 2.3.1. Height}

A pre-set tailor tape is attached to the wall. The total length was set to 2 meters. The height of the students was measured without their shoes. 


\subsubsection{Body Weight}

Body weight measurements of the individuals were made with a floor scale placed on a flat surface. The weight of the individuals was measured without any heavy material other than their clothes.

\subsubsection{Body Mass Index}

Body mass index is determined by determining body weight and height (Lagoglu, 2002). BMI is determined by dividing the body weights of the individuals in kilograms by the square of the heights obtained in meters. BMI is expressed in $\mathrm{kg} / \mathrm{m}^{2}$.

\subsection{4. (Body Weight (kg) / Square of Length Length $\left(\mathrm{m}^{2}\right)$ )}

Height and weight of the individuals were taken. Body mass index values of individuals were calculated with the following formula with these height and weight values. $B M I=\mathrm{kg} / \mathrm{m}^{2}$

\subsubsection{Physical Fitness Parameters Tests}

\subsubsection{Sit-Reach Flexibility Test}

Lie in the sitting position is to reach the farthest point the trunk can reach without bending the knees to the access board. Sit-reach test board, is around $35 \times 55 \mathrm{~cm}$ and $45 \times 32 \mathrm{~cm}$. The upper side of the board is rated between $\mathrm{O}-50 \mathrm{~cm}$. After the individual sits with his feet touching the lower part of the board, he reaches the last point he can reach without bending his knees. The test should be performed 2 times and best value is recorded.

\subsubsection{Flamingo Balance Test}

First, the individual is allowed to make an experiment in order to decide which leg to do the test. It is the measurement of the time the individual can stand on the balance for a given period of time. There is a chance to hold the other free foot with the same hand while standing on one foot. If subject loses balance more than 15 times during the first 30 seconds of the test, the test is considered invalid. Flamingo balance value is the longest time an individual can stay on one foot in balance, the best time is recorded (Pense \& Serpek, 2010).

\subsubsection{Standing Long Jump Test}

The individual's toe tips should be placed just behind the line while the feet are in the anatomical position. Parallel to the ground, the arms should be in the front and the knees in the bent position, subject should jump to the forward with swing of arm. The meter to be measured is fixed on a straight line. When the individual makes the jump, the heel of the foot closest to zero should be taken as reference. It should be measured with a ruler. After two trials the best score is recorded in $\mathrm{cm}$.

\subsection{8. $10 x 5$ Shuttle Run Test}

2 cones placed at a distance of 10 meters. The individual is ready behind the starting line. With the start command, subject runs as fast as possible, crossing two lines on both feet, crossing the opposite line and back to the starting line. Repeats 5 times until a total of 50 meters is reached and the running time is recorded.

\subsubsection{Meters Sprint Test}

On a flat surface of 30 meters, individuals run at maximal speed in the designated area with 2 cones at the beginning and end. Individuals must warm up at slow pace before the test. Then subjects should be ready for testing by making stretching movements. The information about test should be explained to the individual.

\subsubsection{T Agility Test}

T-test can be defined by the individual's right-lefti, forward and backward runs. The individual must perform these runs as quickly as possible in a particular area. There should be a warm-up period of 15 minutes before starting the test. The athlete must touch the center cone with his right hand. Then he should run $5 \mathrm{~m}$ to the left and slide with his left hand. It should then run to the cone at a distance of $10 \mathrm{~m}$ with a side-sliding step and touch it with the right hand. Finally, the athlete must go to the middle cone with a side-sliding step, touch with his left hand and stop the photocell when he returns back to the beginning of the $\mathrm{T}$.

\subsubsection{Meters Shuttle Run Test}

The individual runs round-trip at a distance of 20 meters (flat ground). The running speed is adjusted according to the signals that play at certain intervals. The individual must start running on signal 1 and be on the other line until signal 2. At the beginning the pace is slow but it increases by time. If the individual is two times late for the signal, the test is terminated. The individual must undergo a detailed warm-up period before taking the test. The test information should be explained in detail.

\subsection{Data Analysis}

In the research, values were compared by using SPSS 16.0 Package program. For the analysis of the values, Kolmogrov-Smirnov test was first applied to evaluate whether they show normal distribution. As a result of Kolmogrov-Smirnov normal distribution test analysis, flexibility test of values $(p=0,018<0,05)$, balance test $(p=$ $0,000<0,05), 10 \times 5$ shuttle test $(\mathrm{p}=0,012<0,05)$, t-agility test $(\mathrm{p}=0.008<0.05), 30$ meters sprint test $(\mathrm{p}=0.023$ $<0.05)$, standing long jump test $(p=0.002>0.05)$, 20 meters shuttle test $(p=0.001>0.05)$ which did not show normal distribution. Mann-Whitney $\mathrm{U}$ test was used to analyze whether there was a significant difference between the data because the findings did not show normal distribution. Significance value was taken as $\mathrm{p}<0.01$ and $\mathrm{p}$ $<0.05$. 


\section{Findings}

In this study; the physical fitness parameters of the first-grade male students with a mean age of $7.15 \pm 36$ years were examined. Sub-problems of the findings obtained as a result of the analysis of the collected data are presented. The results were evaluated according to correlation coefficients between 0.05 and 0.01 with significant difference and no significant difference.

When the statistical values were analyzed by Kolmogrov-Smirnov Test, it was seen that it did not show normal distribution. Statistical analysis was evaluated by Mann-Withney-U test because the statistical values did not show normal distribution. During this study, students receiving physical education courses take $40+40$ min 2 days a week. In addition to the physical education courses, the students studying in different branches train for 1.30 hours two days a week. In this context, statistical analyzes of physical fitness parameters are given.

\begin{tabular}{c|c|c|c|c|c|c|c}
\hline Group & N & T-agility test & Mean Rank & Sum of Rank & U & p value \\
\hline Different Sport Branches & 25 & $19.08 \pm 2.6$ & 25.26 & 631.50 & 306.50 & \multirow{2}{*}{.009} \\
\cline { 1 - 4 } Physical Education & 40 & $21.31 \pm 3.29$ & 37.84 & 1513.50 & & \\
\hline
\end{tabular}

In Table 1 the results of the Mann Whitney $U$ test of T-Agility Test of the students who take physical education courses and who are trained in different sports branches are given. When Table 1 is examined. there is a significant difference between the students who take physical education courses and who study in different sports branches $(\mathrm{p}=.009<0.05)$.

\begin{tabular}{c|c|c|c|c|c|c}
\multicolumn{8}{c}{ Table-2. Mann-Whitney u test of 30 meter sprint test values (Seconds). } \\
\cline { 1 - 5 } Group & $\mathbf{N}$ & $\mathbf{3 0}$ meters & Mean Rank & Sum of Rank & U & p value \\
\hline Different Sport Branches & 25 & $7.23 \pm .82$ & 24.72 & 618.00 & 293.00 & \multirow{2}{*}{.005} \\
\cline { 1 - 5 } Physical Education & 40 & $8.01 \pm .98$ & 38.18 & 1527.00 & & \\
\hline
\end{tabular}

Table 2 shows the Mann Whitney U test results of the 30-Meter Sprint Test of the students who took a physical education course and trained in different sports branches. When Table 2 is examined. there is a significant difference between the students who take physical education courses and who study in different sports branches $(p$ $=.005<0.05)$.

\begin{tabular}{c|c|c|c|c|c|c}
\multicolumn{7}{c}{ Table-3. Mann-Whitney u test of standing long jump test values (cm). } \\
\hline Group & $\mathbf{N}$ & Standing Long Jump & Mean Rank & Sum of Rank & U & p value \\
\hline Different Sport Branches & 25 & $106.8 \pm 20.6$ & 41.24 & 1031.500 & 294.000 & .005 \\
Physical Education & 40 & $92.12 \pm 19.4$ & 27.85 & 294.000 & & \\
\hline
\end{tabular}

Table 3 shows the results of the Mann Whitney U test of the Standing Long Jump Test of the students who took a physical education course and who were trained in different sports branches. When Table 3 is examined. there is a significant difference between the students who take physical education courses and who study in different sports branches $(\mathrm{p}=.005<0.05)$.

Table-4. Mann-Whitney u test of flamingo balance test values (Seconds).

\begin{tabular}{c|c|c|c|c|c|c}
\hline Group & N & Flamingo Balance test & Mean Rank & Sum of Rank & U & p value \\
\hline Different Sport Branches & 25 & $27.28 \pm 28.31$ & 36.32 & 908.00 & 41 & .263 \\
Physical Education & 40 & $20.34 \pm 18.28$ & 30.92 & 1237.0 & 7 & \\
\hline
\end{tabular}

Table 4 shows the results of the Mann Whitney U test of the Flamingo Balance Test of the students who took a physical education course and received training in different sports branches. When Table 4 was examined. it was observed that the students who were educated in different sports branches were in balance for a longer period of time but there was no significant difference between the two groups $(p=0.263>0.05)$.

Table-5. Mann-Whitney u test of sit-reach flexibility test values $(\mathrm{cm})$

\begin{tabular}{c|c|c|c|c|c|c}
\hline Group & N & Sit-Reach & Mean Rank & Sum of Rank & U & p value \\
\hline Different Sport Branches & 25 & $31.25 \pm 6.70$ & 37.08 & 927.00 & 398.000 & .169 \\
Physical Education & 40 & $28.45 \pm 7.13$ & 30.45 & 1218.00 & & \\
\hline
\end{tabular}

In Table 5 the Mann Whitney U test results of the Sit-Reach Flexibility Test of the students who took a physical education course and received training in different sports branches are given. When Table 5 was examined. it was observed that the flexibility parameters of the students who were educated in different sports branches were at a better level but there was no significant difference between the two groups $(p=0.169>0.05)$.

\begin{tabular}{c|c|c|c|c|c|c}
\multicolumn{7}{c}{ Table-6. Mann-Whitney u test of 10x5 shuttle run test values (seconds). } \\
\hline Group & N & 10x5 Shuttle Run & Mean Rank & Sum of Rank & U & p value \\
\hline Different Sport Branches & 25 & $17.51 \pm 1.28$ & 28.22 & 705.50 & 380.500 & .107 \\
Physical Education & 40 & $18.65 \pm 2.44$ & 35.99 & 1439.50 & & \\
\hline
\end{tabular}

In Table 6 the Mann Whitney $\mathrm{U}$ test results of the 10x 5 Shuttle Run Test of the students who took a physical education course and received training in different sports branches are given. When Table 6 was examined. there was no significant difference between the students who took physical education courses and also received training in different sports branches $(\mathrm{p}=0.107>0.05)$. 
Table-7. Mann-Whitney u test of 20 meter shuttle run test values (Pieces)

\begin{tabular}{c|c|c|c|c|c|c}
\hline Group & N & 20-meter Shuttle Run & Mean Rank & Sum of Rank & U & p value \\
\hline Different Sport Branches & 25 & $44.5 \pm 21.0$ & 32.10 & 802.50 & 477.50 & .761 \\
Physical Education & 40 & $46.82 \pm 19.64$ & 33.56 & 1342.5 & & \\
\hline
\end{tabular}

In Table 7 the Mann Whitney u test results of the 20-Meter Shuttle Run Test of the students who took the physical education course and received training in different sports branches were given. there was no difference $(p$ $=0.761>0.05)$.

\section{Discussion}

According to the results of statistical analysis, agility, speed and explosive force values were found to be significantly different from physical fitness parameters $(\mathrm{p}<0,05)$. There was no significant difference in balance, flexibility and cardiovascular endurance values $(p>0.05)$ between subjects who took the physical education course and received training in different sports branches. According to this information, there are studies with similar results in the literature.

Altınkök, Vazgeçer, and Measurer (2013) in the study of physical education program that includes the development of basic motor movements in the impact of the development of basic motor movements of children aged 5-6 stated that a significant difference between the agility test values of children $(\mathrm{p}<0.001)$. Agility,pre-posttest values, $(p<0.001)$ in the favor of post-test significant differences were found in the experimental group, but no significant difference was found in the control group.

Pekel, Balcı, Mansur, Balcı, and Hamdi (2006) In his study in 2006, evaluated the relationship between physical fitness test results and anthropometric properties in children engaged in sports activity, and found a significant difference between 30-meter sprint tests among individuals $(\mathrm{p}<0.05)$. In the study of the effect of exercise on physical fitness components in children, Saygin et al. (2011) observed that 30-meter sprint test of students with different branch training (basketball, taekwondo) and sedentary students revealed significant results $(p<0,05)$. Diker, in his research in 2013, some physical fitness characteristics of 8-14 age group football players were examined according to age group. When the sprint values of 30 meters were compared, a significant difference was found $(\mathrm{p}<0.05)$.

In 2006, Kizılakayfa (2006) observed a significant difference in the results of the long jump test analysis by stopping the study on the comparison of the results of the application of the eurofit test batteries of the active and non-active students in the 12-14 age group in Edirne city center primary schools. $(\mathrm{p}<0.05)$. Hartman, Niet, and Moolenaar (2014) examined the physical activity and physical fitness parameters of the 8-11 age group. In the study, a significant result was found when the statistical values of the individuals were compared in the standing and long jump test $(\mathrm{p}<0.05)$.

Celik et al. (2013) Evaluated the physical and motoric characteristics of primary school students in the 7-9 age group in 2013 and observed that there was no significant difference between the flexibility parameters of the students ( $\mathrm{p}>0.05)$. Hartman et al. (2014) examined the physical activity and physical fitness parameters of the 8-11 age group in 2014 and there was no significant difference between the flexibility parameters among the individuals $(\mathrm{p}>0.05)$.

In his study of the effect of birth weight on physical fitness parameters in children aged 8-10 years, Ozen (2014) observed no significant difference in the 10x5 shuttle run test analyzes among individuals $(p>0.05)$. Ranson, Stratton, and Taylor (2015) In the study in which the elementary school students examined the physical fitness parameters using the eurofit test battery in 2015, 10x 5 shuttle run test results of the male students did not appear $(\mathrm{p}>0.05)$.

Hartman et al. (2014) examined the physical activity and physical fitness parameters of the 8-11 age group observed no significant difference between the results of the 20-meter shuttle run test analysis ( $\mathrm{p}>0.05)$.

As a result, in addition to the physical education course, it was determined that the physical fitness parameters of male students studying in different branches were higher. As a result of the study, since the speed, agility and muscular force parameters developed faster in males, it was observed that the values of the students studying in different branches were at a better level and there was a significant difference between them.

\section{References}

Altınkök, M., Vazgeçer, E., \& Measurer, B. (2013). Investigation of the effect of physical education program design involving the development of basic motor movements on the development of basic motor movements of children aged 5-6. International Turkish Journal of Educational Sciences, 1(1), 74-87.

Baltacı, G. (2008). Children and Sports. Ankara: Ministry of Health Publications.

Celik, A., Günay, E., \& F., A. (2013). Evaluation of physical and motoric features of 7-9 age group primary school students. Dokuz Eylul University Faculty of Medicine Journal, 27(1), 7 - 13.

Emiroğlu, O. (2004). Eurofit test battery application for 7-11 year old primary school students. Master Thesis. University of Nicosia. Cyprus.

Hartman, E., Niet, A., \& Moolenaar, B. J. (2014). Relationship between physical activity and physical fitness in school-aged children with developmental language disorders. Research In Developmental Disabilities, 35(12), 3285-3291. Available at: https://doi.org/10.1016/j.ridd.2014.08.022.

Kesilmis, I. (2012). The effect of gymnastic training on growth and biomotor abilities in children aged 4-6. Master Thesis. Mersin University. Myrtle.

Kızılakayfa, E. (2006). Comparison of the application results of eurofit test batteries for students who are active in the 12-14 age group in Edirne city center primary schools and who do not do sports (who attend physical education classes). Master Thesis. University of Trakya. Edirne.

Lagoglu, M. (2002). Evaluation of the physical fitness levels of 12 years old children with the battery of eurofit. Master Thesis. Selçuk University. Konya.

Ozen, G. (2014). The effect of birth weight on some physical fitness parameters of 8-10 years old children. Master Thesis. İnönü University. Malatya.

Pekel, H., Balcı, E., Mansur, O., Balcı, S. S., \& Hamdi, P. (2006). Evaluation of the relationship between performance-related physical fitness test results and anthropometric properties in children doing sports. Kastamonu Education Journal, 1(14), 299-308.

Pense, M., \& Serpek, B. (2010). Determination of physiological and biometric properties of female students playing basketball between the ages of 14-16 with eurofit test battery. Selcuk University Physical Education Sports Sciences Journal, 12(3), 191-198.

Ranson, R., Stratton, G., \& Taylor, S. (2015). Digit ratio (2D: 4D) and physical fitness (Eurofit test battery) in school children. Early Human Development, 91(5), 327-331. Available at: https://doi.org/10.1016/j.earlhumdev.2015.03.005. 
Saygın, E., Karacabey, K., \& Saygın, O. (2011). Investigation of physical activity and physical fitness factors in children. International Journal of Human Sciences, 8(2), 92 1-935.

Yenal, T., Çamliyer, H., \& Saracaloğlu, A. (1999). The effect of physical education and sports activities on motor skills and abilities in primary school second period children. Gazi Journal of Physical Education and Sports Sciences, 4(3), 15-16.

Zorba, E. (2001). Physical fitness. Ankara: Gazi Bookstore. 